\title{
Study on optimal conditions of flocculation in deinking wastewater treatment
}

\author{
Ming $\mathrm{Li}^{i^{*}}\left(\mathrm{D}\right.$, Kaitang $\mathrm{Hu}^{2}$ and Jin $\mathrm{Wang}^{3}$
}

\author{
* Correspondence: minglilm@umich. \\ edu \\ ${ }^{1}$ Department of Mathematics \& \\ Applied Sciences, University of \\ Michigan-Flint, Flint, USA \\ Full list of author information is \\ available at the end of the article
}

\begin{abstract}
Flocculation is an important method to treat paper manufacturing wastewater. Coagulants and flocculants added to wastewater facilitate the aggregation and sedimentation of various particles in the wastewater and lead to the formation of floc networks which can be easily removed using physical methods. The goal of this paper is to determine the optimal hydraulic conditions using machine learning in order to enable efficient flocculation and improve performance during the treatment of deinking wastewater. Experiments using polymerized aluminum chloride as flocculant to treat deinking wastewater were carried out. Based on the orthogonal array test, 16 different combinations of hydraulic conditions were chosen to investigate the performance of flocculation, which was indicated by the turbidity of the solution after treatment. To develop a model representing the relationship between the hydraulic conditions and the performance of wastewater treatment, the machine learning methods, support vector regression and Gaussian process regression, were compared, whereby the support vector regression method was chosen. According to the fitness function derived from the support vector regression model, a genetic algorithm was applied to evaluate the optimal hydraulic conditions. Based on the optimal conditions determined by the genetic algorithm and real-life experience, a set of hydraulic conditions were implemented experimentally. After treatment under higher stirring speed at $120 \mathrm{rpm}$ for $1 \mathrm{~min}$ and lower stirring speed at $20 \mathrm{rpm}$ for $5 \mathrm{~min}$ at a temperature of $20^{\circ} \mathrm{C}$, the turbidity of deinking wastewater was measured as 1 NTU. The turbidity reduction was as high as $99.6 \%$, which indicated good performance of the deinking wastewater treatment.
\end{abstract}

Keywords: Deinking wastewater, Flocculation, Gaussian progress regression, Genetic algorithm, Hydraulic conditions, Support vector regression

\section{Introduction}

Water is one of the most essential natural resources for the basic necessities of life. It is a scarce resource because water shortages already exist in many regions. The challenge presented by water scarcity will be exacerbated since climate change is aggravating the contradiction between world development and water demand [1]. In order to address this problem, researchers have been developing technologies to enhance water

(c) The Author(s). 2021 Open Access This article is licensed under a Creative Commons Attribution 4.0 International License, which permits use, sharing, adaptation, distribution and reproduction in any medium or format, as long as you give appropriate credit to the original author(s) and the source, provide a link to the Creative Commons licence, and indicate if changes were made. The images or other third party material in this article are included in the article's Creative Commons licence, unless indicated otherwise in a credit line to the material. If material is not included in the article's Creative Commons licence and your intended use is not permitted by statutory regulation or exceeds the permitted use, you will need to obtain permission directly from the copyright holder. To view a copy of this licence, visit http://creativecommons.org/licenses/by/4.0/. The Creative Commons Public Domain Dedication waiver (http://creativecommons.org/publicdomain/zero/1.0/) applies to the data made available in this article, unless otherwise stated in a credit line to the data. 
supplies and optimize water resource management so that the efficiency of the usage of water can be improved $[1,2]$.

Wastewater reclamation and reuse are promising solutions to cope with water scarcity. They can expand water supplies, provide environmental benefits and increase economical sustainability. The successful wastewater reclamation and reuse depend on the development of wastewater treatment technologies. Usually, wastewater treatment includes primary, secondary, and tertiary treatment. Primary treatment clarifies wastewater by the separation of larger solids. Secondary treatment removes the dissolved and suspended organic matter in the effluent from primary treatment. Tertiary treatment further purifies wastewater so that it can be used for industrial, agricultural, and municipal supplies [3].

The paper-making industry generates a great amount of wastewater, which is a major pollution source around the world. The treatment of wastewater in pulp and paper mills has attracted attention from researchers for decades $[4,5]$. As wastepaper recycling continues to increase because of economic and environmental initiatives, deinking becomes one of the most important steps that determine the performance of wastewater treatment [6]. Deinking is to remove the printing ink from newsprint, printed paper, and so on, when these papers are defibrated for wastepaper recycling [7]. Flotation deinking is the most widely used deinking technology, and the other methods used for deinking are bleaching deinking, enzymatic deinking, and washing deinking, etc. [8, 9]. The wastewater during paper deinking processes is of a very complex composition, including a large number of ink particles, fine fibers, fillers, paper additives, and other substances [10]. The characteristics of the wastewater after deinking processes are different depending on the deinking technologies, which leads to the various wastewater treatment methods adopted. For example, the deinking wastewater after enzymatic deinking has low biological oxygen demand (BOD) and chemical oxygen demand (COD), and it is hard to be biodegraded [11]. Like other wastewater, the deinking wastewater treatment mainly includes physical, chemical, and biological treatment processes $[12,13]$. Physical treatment can remove suspended solids through filtration, sedimentation, flotation, and so on, which is used in primary and tertiary treatment [14]. Chemical treatment methods include coagulation and flocculation, adsorption, oxidation, etc., and they also can be used in primary and tertiary treatment [12]. The deinking wastewater is commonly pretreated using coagulation and flocculation to reduce the cost and improve the performance of wastewater treatment [15]. Biological processes such as fungal treatment, aerobic, and anaerobic digestion, are used for secondary treatment $[5,16]$. In order to improve the performance of deinking wastewater treatment, an integrated system with multiple treatment methods is usually implemented [15, 17]. Simstich et al. used a thermophilic aerobic membrane bioreactor, which was a combination of biological treatment and ultrafiltration, to treat deinking wastewater [18]. Yu et al. combined coagulation and flocculation, activated sludge process, and a Fenton reaction system for primary, secondary, and tertiary treatment [13].

Coagulation and flocculation have long been utilized to process water and wastewater. In addition, they can be applied to various industries to remove miscellaneous contaminants because of their effectiveness and convenience. Coagulants and flocculants are chemical agents that can be used to complete the two-phase process, coagulation 
and flocculation, to remove contaminants [19]. Coagulants added to wastewater destabilize the suspended particles and allow for the aggregation and sedimentation of suspended particles, while flocculants are bridging compounds and they facilitate the formation of floc. Floc is the networks of clustering micro-floc and macro-floc of aggregated fine particles, which can be efficiently removed by physical methods [20].

The primary condition of forming floc in wastewater is the contact and collision among the various particles. There are three main ways for the particles to come into contact with each other in wastewater: the Brownian movement of the particles, collisions caused by differences in the particles' settling velocities, and the hydraulic effect of the flowing water especially the shear conditions [21]. The contact and collision caused by Brownian motion are significant if the particles are small enough. As the networks of floc increase, the effect due to Brownian movement is negligible [22]. The second way of collision and aggregation can be due to the different settling speeds among particles. It does play a role in floc formation and sedimentation. However, compared with the strong disturbance of water flow in the flocculation jar during mixing processes, the effect of relatively low settling speeds among particles is limited [22]. Especially at the initial stage of flocculation, the particles are small, their settling speeds are low, and the difference among the settling speeds is even smaller. Thus, the contact and collision of particles mainly depend on the hydraulic effect of the flowing water in the flocculation jar [22]. Rapid mixing is crucial because it facilitates the growth of floc by expediting the dispersion of coagulants and improving the collision efficiency of suspended containments. Though, high intensity and long duration of rapid mixing cause micro-floc breakage and reduce floc re-growth potential [23, 24]. Slow stirring takes longer, and usually, the floc size is constant indicating a dynamic balance between floc growth and break [23]. The increase of slow stirring speed results in the decrease of steady-state floc size. The hydraulic conditions significantly affect coagulation and flocculation processes, which in turn determine the performance of deinking wastewater treatment [21]. However, modeling coagulation and flocculation processes is complex, and there are contradictory recommendations of hydraulic conditions in the literature [23]. Therefore, it is imperative to better understand the relationship between the hydraulic conditions and the efficiency of flocculation in order to address complex wastewater treatment issues. The goal of this paper is to evaluate the optimal hydraulic conditions that enable efficient flocculation and result in a substantial reduction of the turbidity of deinking wastewater.

Machine learning is a family of algorithms that enable computers to accomplish tasks through learning from usually limited datasets presented to them, where information about the task is not available thoroughly. Machine learning techniques have an extensive variety of applications in all aspects of modern life, including classification, recognition, optimization, prediction, and so on. As awareness of environmental issues rises, machine learning algorithms have seen a wide range of applications in wastewater treatment [25-27]. In this paper, machine learning methods were utilized to examine the hydraulic conditions for efficient flocculation during the treatment process of deinking wastewater. Support vector machines (SVM), Gaussian process regression (GPR), and genetic algorithms (GA) are frequently used machine learning algorithms. Researchers have been inspired to take advantage of these algorithms to explore new applications [28-30] 
Support vector machines are supervised learning algorithms that can be utilized for classification and regression analysis. SVMs determine the decision boundary by constructing the maximum margin hyperplane which has the maximum distances with the nearest data points of all separated classes [31]. SVMs can choose different kernel functions appropriately to perform not only linear classification but also nonlinear classification in a higher-dimensional space [32]. In contrast to neural networks, SVMs do not need a large number of observation data for training, which is suitable for tasks with limited prior data. SVMs are relatively easy to implement, and their training speed is fast. SVMs are also one of the most robust prediction algorithms. Therefore, SVMs have been extensively applied to solve real-world problems.

Support vector regression (SVR) utilizes the same principles as SVMs to implement regression analysis. SVR can interpret the datasets presented to it and identify the underlying relationship between the input variables and the output response in order to predict a decision outcome [33, 34]. The essential goal of SVR is to find the most appropriate function over the training datasets, which is the hyperplane that has the maximum number of data points.

Gaussian process regression is another machine learning method to solve nonlinear regression problems. It is a nonparametric Bayesian approach using probability distribution to estimate and predict uncertainties [35]. Since GPR does not focus on individual data samples, it can work well with smaller datasets [36]. Moreover, GPR can use kernel functions to integrate prior knowledge to capture the inherent properties in the sample datasets. Appropriate selections of kernel functions can optimize the modeling of observed datasets [37].

Genetic algorithms belong to the family of evolutionary algorithms (EAs) which are inspired by Darwin's theory of evolution. Individuals in a population undergo descent with modification, and the mechanism of natural selection leads to the survival of the fittest individuals. GAs are adaptive heuristic search algorithms that have been extensively utilized in global optimization [38]. In order to find the optimal solution of a fitness function, individuals of a population generated randomly have to go through the evolution of generations by selection, crossover, migration, and mutation [39]. The iterative processes terminate when the population has converged, i.e., the change of the population can be ignored or the maximum number of generations has been reached.

In this study, the performance of flocculation in the deinking wastewater treatment, which was induced by different hydraulic conditions in the flocculation jar, was investigated. The performance of flocculation was indicated by the measured turbidities after each treatment. The hydraulic conditions included the fast stirring speed and time, low stirring speed and time, and temperature. The boundary values for hydraulic conditions are infinite since any speed, time and temperature could be chosen to conduct the coagulation and flocculation processes. In order to simplify the task, each condition was divided into four levels which are frequently adopted. The effect on the performance of wastewater treatment was examined under different combinations of these levels.

Based on the orthogonal array test, 16 different combinations of hydraulic conditions were implemented, and the corresponding turbidity was measured after each run. Machine learning methods were utilized to analyze the experimental results and determine the optimal hydraulic conditions. The machine learning methods used in this study were provided by MATLAB toolboxes. Both SVR and GPR were adopted to model the 
relationship between the hydraulic conditions and the performance of deinking wastewater treatment. The performance of the two methods was compared to determine which model represented the experimental data better. SVR was chosen to develop the model relating the hydraulic conditions to the performance of wastewater treatment. After the model was set up, GA was applied to evaluate the optimal combination of the hydraulic conditions resulting in the best performance of wastewater treatment, i.e., the lowest turbidity. GA determined the optimal conditions based on the fitness function, the constraints, and the upper and lower bounds. Taking into account the real-life conditions of flocculation, a set of hydraulic conditions was adopted.

\section{Methods}

The deinking wastewater was obtained from a paper mill of a newspaper company that uses froth floatation for deinking. During the deinking process, air is blown into a tank containing suspended pulp recovered from wastepaper. Air bubbles transport ink and other contaminant particles to the surface and form a froth layer that can be skimmed easily. The effluent of this process was the deinking wastewater used in this study. Its properties are listed in Table 1. The turbidity was measured as 275 NTU. Turbidity refers to the light scattering in water due to the presence of suspended solids, which makes the water appear cloudy. In this study, turbidity was measured in nephelometric turbidity units (NTU) using a turbidity meter. The turbidity meter was calibrated first by standard solutions and then utilized to measure the turbidities of deinking wastewater before and after treatment.

The coagulant and flocculant used in this experiment was polymerized aluminum silicate chloride prepared in the lab. It has larger molecular weight and can improve the strength of bridge formation and the performance of coagulation [40, 41]. It was prepared by introducing polymerized silicic acid solution into polyaluminum chloride solution. It was constituted of $7.8 \% \mathrm{Al}_{2} \mathrm{O}_{3}$, the basicity was $45 \%$, the density was $1.2 \mathrm{~g} / \mathrm{cm}^{3}$, the $\mathrm{Al} / \mathrm{Si}$ ratio was $2 / 1$, and the $\mathrm{pH}$ value was 3.4.

A 100-ml deinking wastewater sample was used in the experiment. It was stirred well and carefully in the flocculation jar to prepare for the experiment. Then polymerized aluminum silicate chloride including $80 \mathrm{mg} / \mathrm{l}$ of the active ingredient $\mathrm{Al}_{2} \mathrm{O}_{3}$ was added to initiate the coagulation and flocculation processes. First, the solution was stirred at a

Table 1 Properties of deinking wastewater

\begin{tabular}{lll}
\hline Wastewater indicator & Deink \\
\hline Temperature $\left({ }^{\circ} \mathrm{C}\right)$ & & 32 \\
$\mathrm{pH}$ & & 9.21 \\
$\mathrm{COD}_{\mathrm{cr}}(\mathrm{mg} / \mathrm{l})$ & & 1050 \\
Density $\left(\mathrm{g} / \mathrm{cm}^{3}\right)$ & & 1.002 \\
Viscosity $(\mathrm{cP})$ & & 1.2067 \\
Light transmission $(\%)$ & & 2.4 \\
Turbidity (NTU) & & 275 \\
Solid content & Sedimentable solids $(g / l)$ & 1.38 \\
& Filterable solids $(g / l)$ & 0.291 \\
& Soluble solids $(g / l)$ & 2.158 \\
& Total solids $(g / l)$ & 3.829 \\
\hline
\end{tabular}


higher speed for a certain amount of time, and then it was stirred at a lower speed for a certain amount of time. After the stirring stopped, the solution was allowed to settle for $30 \mathrm{~min}$ so that the floc networks could sediment to the bottom of the jar. Then the upper layer liquid about 20 to $30 \mathrm{~mm}$ from the surface was extracted and its turbidity was measured. This experiment was repeated under different hydraulic conditions which were separated into four levels as listed in Table 2.

Although the hydraulic conditions included five categories and four levels, the combinations of the hydraulic conditions were too large to be experimented on. Instead of testing the hydraulic conditions exhaustively, 16 different combinations were chosen to conduct the experiment, based on the orthogonal array test. After each run of the different conditions, the turbidity was measured to examine the performance of wastewater treatment. The goal was to find the optimal hydraulic conditions that could expedite the formation and sedimentation of floc networks. Thus, the performance of the wastewater treatment would be improved and the turbidity measured would be the lowest, ideally.

\section{Results and discussion}

The 16 different combinations of hydraulic conditions and the measured turbidities after each experiment were shown in Table 3.

The relationship between the hydraulic conditions and the performance of wastewater treatment was first evaluated by SVR. The training datasets included the hydraulic conditions as the variables and the according turbidities as the response. The five-fold cross-validation was implemented to avoid overfitting, though the ten-fold crossvalidation was found to be a better practice [42]. Because the training datasets only had the limited 16 experimental observations, the five-fold cross-validation was adopted. Based on the model determined by the SVR with a linear kernel, the predicted turbidities according to the 16 different hydraulic conditions were illustrated in Fig. 1, as compared with the true value of the measured turbidities. This model could also be applied to estimate and predict new datasets. Figure 2 shows the progress to minimize the error of each iteration. The RMSE (root mean square error) of the model was 2.634 and the $R^{2}$ was 0.65 . Figure 2 also highlights the best point hyperparameters and the minimum error hyperparameters.

GPR solves nonlinear regression problems based on probability distributions. It is a supervised learning model and can take advantage of prior knowledge by kernel functions. GPR aims to identify the underlying relationship in the training datasets and predict the response of new inputs assuming they have the similar relationship. In this paper, a GPR model with a squared exponential kernel was developed to represent the

Table 2 Different hydraulic conditions

\begin{tabular}{llllll}
\hline Level & $\begin{array}{l}\text { High-stirring } \\
\text { speed }(\mathbf{r p m})\end{array}$ & $\begin{array}{l}\text { High-speed stirring } \\
\text { time }(\mathbf{m i n})\end{array}$ & $\begin{array}{l}\text { Low-stirring } \\
\text { speed }(\mathbf{r p m})\end{array}$ & $\begin{array}{l}\text { Low-speed stirring } \\
\text { time }(\mathbf{m i n})\end{array}$ & $\begin{array}{l}\text { Temperature } \\
\left({ }^{\circ} \mathbf{C}\right)\end{array}$ \\
\hline 1 & 60 & 0.5 & 20 & 0.5 & 0 \\
2 & 80 & 1 & 40 & 1 & 10 \\
3 & 100 & 2 & 60 & 2 & 20 \\
4 & 120 & 3 & 80 & 5 & 30 \\
\hline
\end{tabular}


Table 3 Combinations of hydraulic conditions

\begin{tabular}{llllllll}
\hline $\begin{array}{l}\text { High- } \\
\text { stirring } \\
\text { speed }(\mathbf{X} 1)\end{array}$ & $\begin{array}{l}\text { High-speed } \\
\text { stirring time } \\
\text { (X2) }\end{array}$ & $\begin{array}{l}\text { Low- } \\
\text { stirring } \\
\text { speed }(\mathbf{X} 3)\end{array}$ & $\begin{array}{l}\text { Low-speed } \\
\text { stirring } \\
(\mathbf{X} \text { time }\end{array}$ & $\begin{array}{l}\text { Temperature } \\
(\mathbf{X} 5)\end{array}$ & $\begin{array}{l}\text { Turbidity } \\
\text { (NTU) }(\mathbf{Y})\end{array}$ & $\begin{array}{l}\text { Reduction of } \\
\text { turbidity (\%) }\end{array}$ \\
\hline 1 & 1 & 1 & 1 & 1 & 1 & 6 & $97.81 \%$ \\
2 & 1 & 2 & 2 & 2 & 2 & 10 & $96.35 \%$ \\
3 & 1 & 3 & 3 & 3 & 3 & 12 & $95.62 \%$ \\
4 & 1 & 4 & 4 & 4 & 4 & 15 & $94.53 \%$ \\
5 & 2 & 1 & 2 & 1 & 4 & 6 & $97.81 \%$ \\
6 & 2 & 2 & 1 & 2 & 3 & 5 & $98.18 \%$ \\
7 & 2 & 3 & 4 & 3 & 2 & 3 & $98.91 \%$ \\
8 & 2 & 4 & 3 & 4 & 1 & 12 & $95.62 \%$ \\
9 & 3 & 1 & 3 & 1 & 2 & 4 & $98.54 \%$ \\
10 & 3 & 2 & 4 & 2 & 1 & 6 & $97.81 \%$ \\
11 & 3 & 3 & 1 & 3 & 4 & 2 & $99.27 \%$ \\
12 & 3 & 4 & 2 & 4 & 3 & 3 & $98.91 \%$ \\
13 & 4 & 1 & 4 & 1 & 3 & 4 & $98.54 \%$ \\
14 & 4 & 2 & 3 & 2 & 4 & 4 & $98.54 \%$ \\
15 & 4 & 3 & 2 & 3 & 1 & 1 & $99.64 \%$ \\
16 & 4 & 4 & 1 & 4 & 2 & 2 & $99.27 \%$ \\
\hline
\end{tabular}

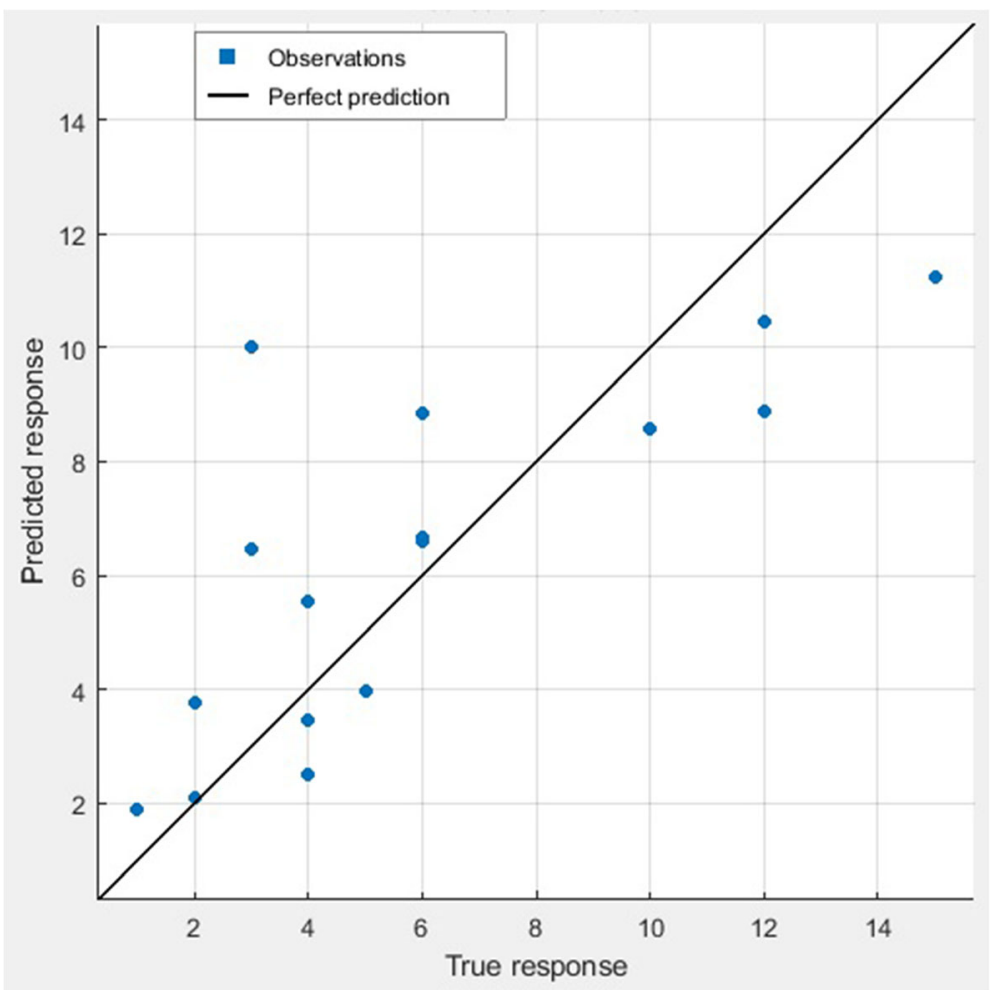

Fig. 1 Actual observations vs. predicted by SVR 


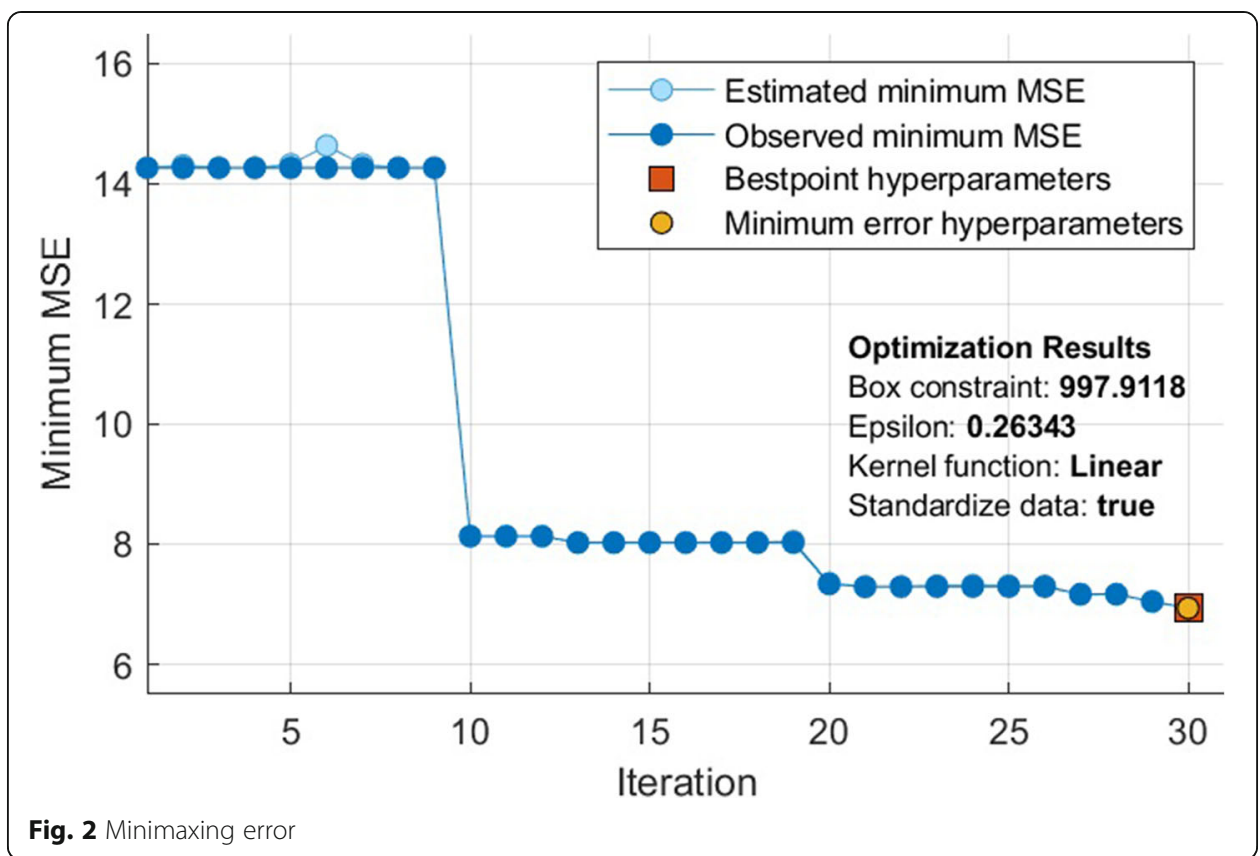

experimental data. Equation (1) shows the squared exponential kernel which is the covariance function of the training datasets.

$$
k(\boldsymbol{x} i, \boldsymbol{x} j)=\sigma_{f}^{2} \exp \left[-\frac{1}{2} \frac{\left(\boldsymbol{x}_{\boldsymbol{i}}-\boldsymbol{x}_{\boldsymbol{j}}\right)^{T}\left(\boldsymbol{x}_{\boldsymbol{i}}-\boldsymbol{x}_{\boldsymbol{j}}\right)}{\boldsymbol{\sigma}_{l}^{2}}\right]
$$

where $\sigma_{f}$ and $\sigma_{l}$ are hyperparameters: $\sigma_{f}$ is the standard deviation of the signal span, and $\sigma_{l}$ is the characteristic length scale [43].

Figure 3 shows the comparison of the GPR predicted turbidities versus the actual measured turbidities based on the 16 different hydraulic conditions. It is obvious that the performance of GPR was not as good as SVR, the RMSE of the estimation of GPR was 3.35 , and the $R^{2}$ was 0.44 . Since the SVR model expressed the inherent relationship of the training datasets better, the SVR model was chosen over the GPR model to estimate and predict the turbidities based on various hydraulic conditions.

GA can perform heuristic optimization in order to find the global optimum. It randomly generates an initial population and searches for the global optimum through a series of evolutionary operations. The iterative process includes [44, 45]:

- Selection: select the parents to generate the next generation of the population according to the fitness function

- Crossover: combine the genetic information of two parents to form the children for the next generation

- Mutation: alter gene values of individual parents randomly to generate new offspring

The GA in the MATLAB toolbox was used to select the optimal conditions for flocculation. The fitness function was derived from the SVR model and was set up to find

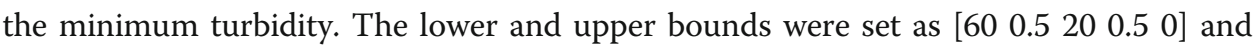
[120 5805 30], which were the minimum and maximum values of the higher stirring 


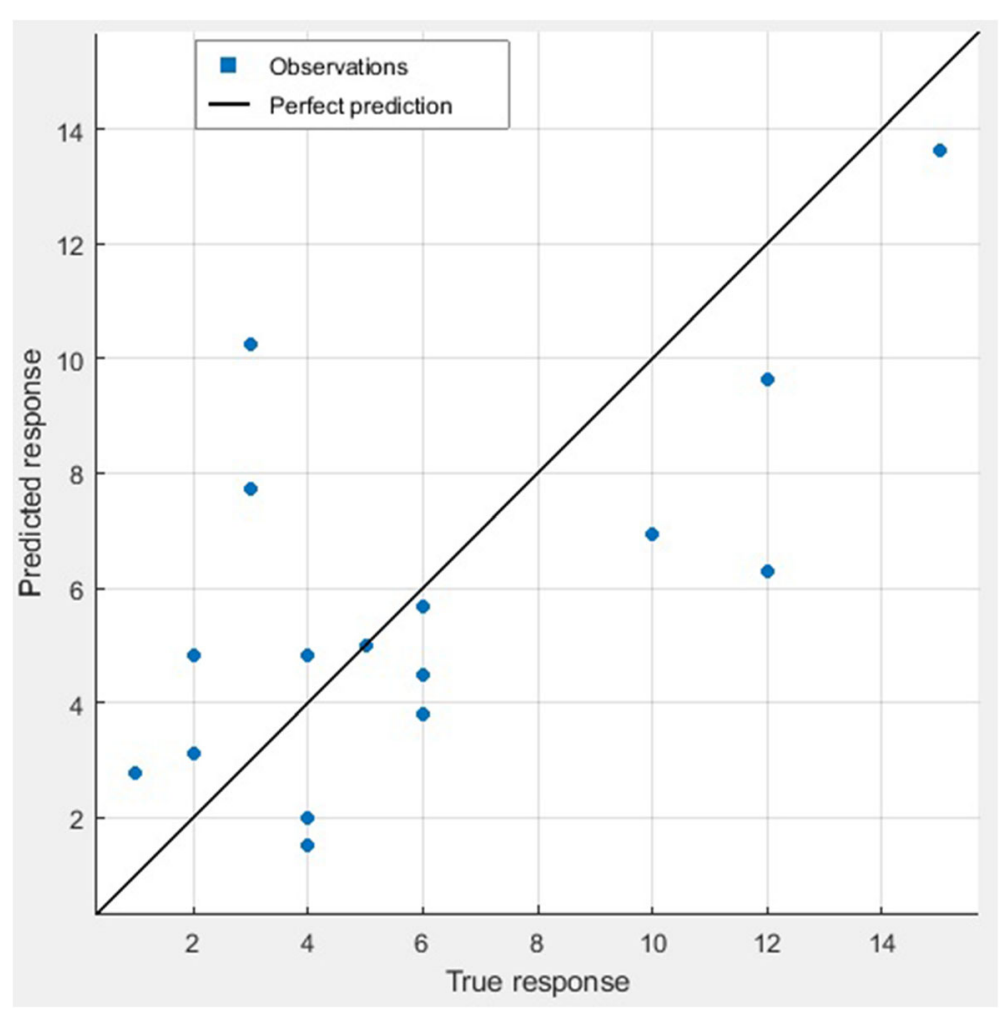

Fig. 3 Actual observations vs. predicted by GPR

speed, higher speed stirring time, lower stirring speed, lower speed stirring time, and temperature, respectively. The lower and upper bounds of the stirring speeds and time were determined based on the equipment and operating conditions in the paper mill. The temperature was based on the manufacturing environment of the paper mill. The other settings adopted the default value as follows:

- Population: double vector with a size of 50

- Selection: tournament with a size of 2

- Crossover fraction: 0.8

- Mutation function: constraint dependent

- Migration: direction as forward and fraction as 0.2

The optimal result was [118.28 0.8223 .974 .98 7.5], and Fig. 4 shows the decrease of the diversity of subsequent generations during the evolution.

From the optimal conditions determined by the GA, and the real-life conditions of flocculation, the following hydraulic conditions were chosen, as shown in Table 4. The deinking wastewater sample was treated under these conditions. After the treatment, the turbidity was measured as $1 \mathrm{NTU}$ and the turbidity reduction was $99.6 \%$, which indicated that the performance of the treatment was satisfactory.

Figure 5 shows the absolute correlation coefficients of hydraulic conditions with turbidity. High-stirring speed was negatively related to turbidity, and the correlation coefficient was -0.75 . The other hydraulic conditions had positive correlations to turbidity and the correlation coefficient between temperature and turbidity was 0.077 . 


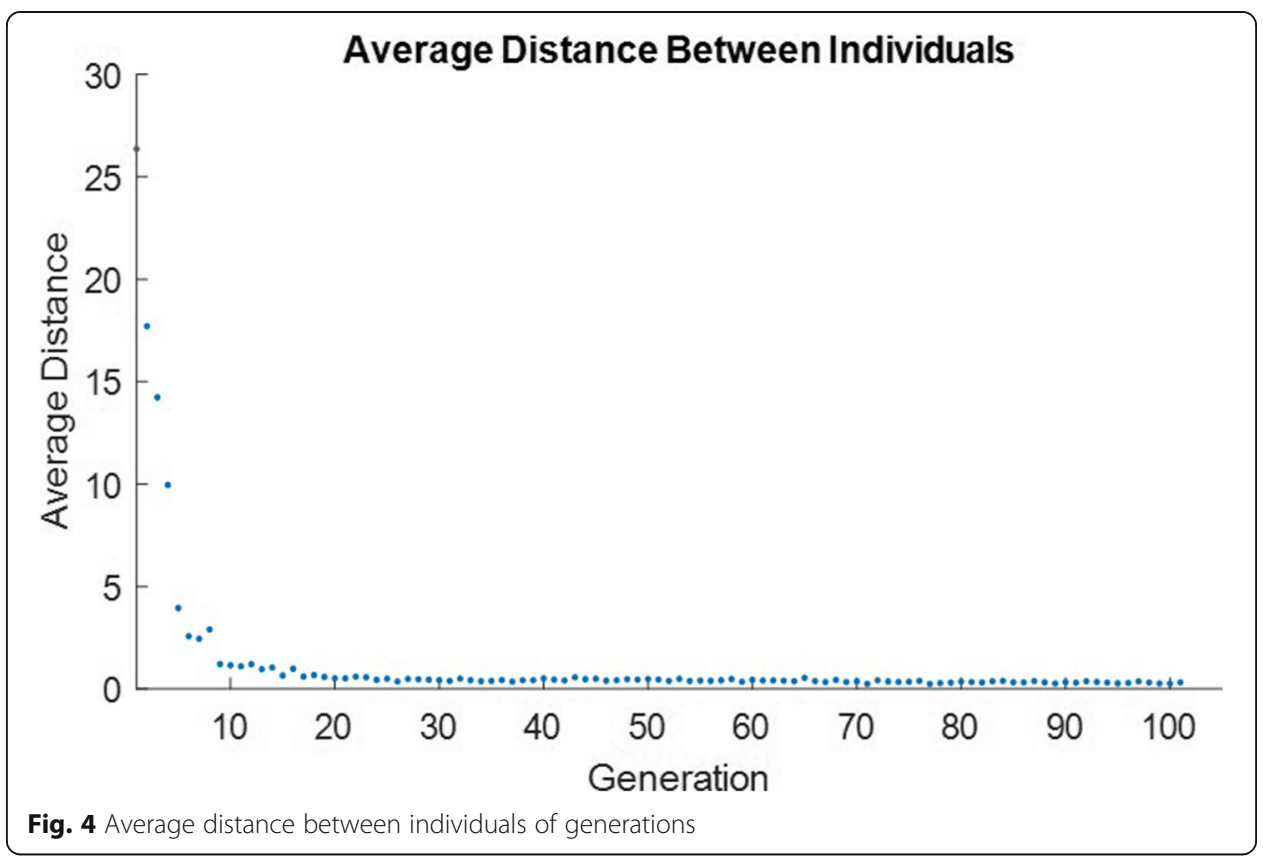

From the results, it can be noticed that at the first stage, the hydrolysis reaction of the coagulant/flocculant happened very fast. A series of Al hydrolysis products e.g. monomers such as $\mathrm{Al}(\mathrm{OH})^{2+}$, polymers such as $\left.\mathrm{Al}_{3} \mathrm{O}_{4}(\mathrm{OH})\right)_{24}{ }^{7+}$, and amorphous hydroxide precipitate were formed immediately [46]. Charge neutralization of negatively charged aquatic particles adsorbed by hydrolysis products, and sweep flocculation of impurity particles enmeshed in growing hydroxide precipitate enabled the processes of coagulation and flocculation [46]. The coagulant/flocculant needed to be dispersed rapidly and evenly to facilitate floc formation. Thus, highspeed stirring at the beginning of flocculation was necessary to increase the chances for particles to contact and collide [47]. Although temperature was an important factor affecting the rate of hydrolysis, in this very short period of time, the effect of temperature was minimal.

During the second stage, particles continued to accumulate, so it was necessary to stir the solution. But at the same time, the rate of the mechanical mixing needed to be maintained so as not to destruct the formation of floc networks. Therefore, the slow mechanical stirring speed was the main factor in the second stage of floc formation [23]. Floc networks took form by slow mechanical agitation, and this process needed to last for several minutes. The slow stirring time at this stage was also an important factor affecting particle aggregation and sedimentation.

Table 4 Optimal hydraulic condition

\begin{tabular}{llllll}
\hline $\begin{array}{l}\text { High-stirring } \\
\text { speed }(\mathbf{r p m})\end{array}$ & $\begin{array}{l}\text { High-speed stirring } \\
\text { time }(\mathbf{m i n})\end{array}$ & $\begin{array}{l}\text { Low-stirring } \\
\text { speed }(\mathbf{r p m})\end{array}$ & $\begin{array}{l}\text { Low-speed stirring } \\
\text { time }(\mathbf{m i n})\end{array}$ & $\begin{array}{l}\text { Temperature } \\
\left({ }^{\circ} \mathbf{C}\right)\end{array}$ & $\begin{array}{l}\text { Turbidity } \\
(\mathbf{N T U})\end{array}$ \\
\hline 120 & 1 & 20 & 5 & 20 & 1 \\
\hline
\end{tabular}




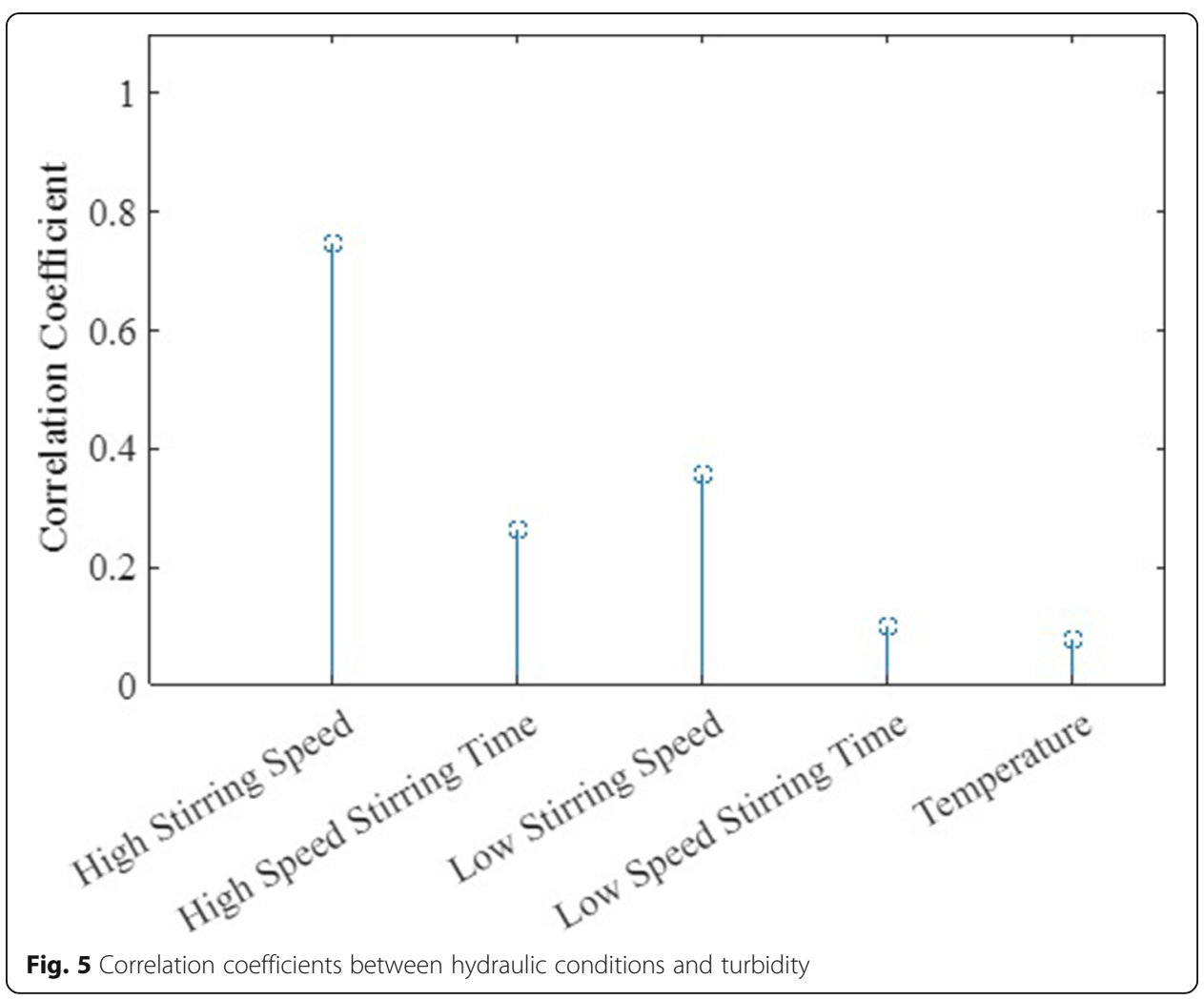

\section{Conclusions}

Using flocculation to treat deinking wastewater depends on the properties of wastewater, flocculants, and other factors. It is necessary to evaluate these factors and determine the optimal conditions to perform wastewater treatment. In this paper, the optimal hydraulic conditions were investigated in order to enable efficient flocculation during deinking wastewater treatment.

Based on the orthogonal array test, 16 experiments were carried out under different combinations of hydraulic conditions, and the corresponding turbidities of the solution were measured after treatment. The relationship between the performance of wastewater treatment, as measured by its turbidity, and the hydraulic conditions was identified by SVR and GPR models. Since the SVR model fit the training datasets better than the GPR model, it was chosen to estimate and predict the performance of wastewater treatment based on the hydraulic conditions. The optimal hydraulic conditions were further examined by the GA according to the fitness function derived from the SVR model. Based on the results determined by the GA and the real-life conditions of flocculation, the optimal hydraulic conditions for deinking wastewater treatment using polymerized aluminum silicate chloride were at $20{ }^{\circ} \mathrm{C}$, the flocculant was added to the wastewater, it was stirred for $1 \mathrm{~min}$ at a fast stirring speed of $120 \mathrm{rpm}$, then stirred for $5 \mathrm{~min}$ at a slow stirring speed of $20 \mathrm{rpm}$, and finally allowing for the solution to settle for $30 \mathrm{~min}$. The turbidity of the liquid was measured as 1 NTU which was $99.64 \%$ reduction of the turbidity of wastewater. 
Therefore, controlling mechanical stirring speed and stirring time was effective to control the formation of floc networks and the performance of deinking wastewater treatment. Using machine learning methods such as SVR and GA can help identify the fundamental relationship between hydraulic conditions and the performance of wastewater treatment. Accordingly, optimal hydraulic conditions can be identified to effectively improve the performance of deinking wastewater treatment.

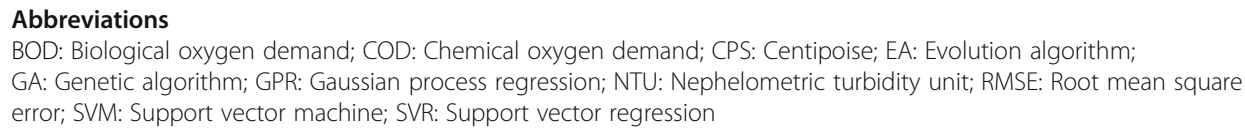

\section{Acknowledgements}

Not applicable

\section{Authors' contributions}

ML conceived and performed the analysis, and was a major contributor in writing the manuscript. KTH interpreted the results, drafted the manuscript, and supervised the project. JW carried out the research methodology, interpreted the results, and drafted the manuscript. The authors read and approved the final manuscript.

\section{Funding}

Not applicable. This study had no funding from any resource.

\section{Availability of data and materials}

All data generated or analyzed during this study are included in this published article.

\section{Declarations}

\section{Competing interests}

The authors declare that they have no competing interests.

\section{Author details}

${ }^{1}$ Department of Mathematics \& Applied Sciences, University of Michigan-Flint, Flint, USA. ${ }^{2}$ Department of Printing Engineering, Yuncheng Professional Technology College, Shanxi, China. ${ }^{3}$ Department of Chemical Control Command Engineering, Beijing Institute of Chemical Defense, Beijing, China.

Received: 16 August 2021 Accepted: 26 October 2021

Published online: 27 November 2021

\section{References}

1. Economidou Y, Doula MK, Zorpas AA (2021) Mitigation of the effects of climate change in the agricultural sector of Cyprus, through optimization of benefit. Water Supply 21(6):2947-2958 https://doi.org/10.2166/ws.2021.118

2. Voukkalia I, Zorpas AA, Stylianouc M, Kostarelosd K (2017) Investigation on the implementation of an in situ process for the treatment of coal tar using standard mixture of surfactants in different CaCl. Desalin Water Treat 65:142-146. https:// doi.org/10.5004/dwt.2017.20248

3. Zorpas AA, Coumi C, Drtil M, Voukalli I, Samaras P (2010) Operation description and physicochemical characteristics of influent, effluent and the tertiary treatment from a sewage treatment plant of the Eastern Region of Cyprus under warm climates. Desalin Water Treat 22(1-3):244-257. https://doi.org/10.5004/dwt.2010.1803

4. Hubbe MA, Metts JR, Hermosilla D, Blanco MA, Yerushalmi L, Haghighat F, Lindholm-Lehto P, Khodaparast Z, Kamali M, Elliott A (2016) Wastewater treatment and reclamation: a review of pulp and paper industry practices and opportunities. BioResources 11(3):7953-8091. https://doi.org/10.15376/biores.11.3. Hubbe

5. Kamali M, Khodaparast Z (2015) Review on recent developments on pulp and paper mill wastewater treatment. Ecotoxicol Environ Saf 114:326-342 https://doi.org/10.1016/j.ecoenv.2014.05.005

6. Pivnenko K, Eriksson E, Astrup TF (2015) Waste paper for recycling: Overview and identification of potentially critical substances. Waste Manag 45:134-142 https://doi.org/10.1016/j.wasman.2015.02.028

7. Saxena A, Singh Chauhan P (2017) Role of various enzymes for deinking paper: a review. Crit Rev Biotechnol 37(5):598612 https://doi.org/10.1080/07388551.2016.1207594

8. Pala H, Mota M, Gama FM (2004) Enzymatic versus chemical deinking of non-impact ink printed paper. J Biotechnol 108(1):79-89. https://doi.org/10.1016/j.jbiotec.2003.10.016

9. Vashisth S, Bennington CP, Grace JR, Kerekes RJ (2011) Column flotation deinking: state-of-the-art and opportunities. Resour Conserv Recycl 55(12):1154-1177. https://doi.org/10.1016/j.resconrec.2011.06.013

10. Pokhrel D, Viraraghavan T (2004) Treatment of pulp and paper mill wastewater-a review. Sci Total Environ 333(1-3):3758 https://doi.org/10.1016/j.scitotenv.2004.05.017

11. Lee CK, Ibrahim D, Ibrahim CO, Daud WR (2011) Enzymatic and chemical deinking of mixed office wastepaper and old newspaper: paper quality and effluent characteristics. BioResources 6(4):3859-3875

12. Zorpas AA, Voukalli I, Loizia P (2012) Chemical treatment of polluted waste using different coagulants. Desalin Water Treat 45:291-296. https://doi.org/10.5004/dwt.2012.3502 
13. Yu G, Peng H, Du C, Chen H, Zhang W (2020) Integrated process combined with fenton reaction for the treatment of papermaking deinking wastewater. J Chem Eng Japan 53(10):653-659 https://doi.org/10.1252/jcej.19we079

14. Gönder ZB, Arayici S, Barlas H (2011) Advanced treatment of pulp and paper mill wastewater by nanofiltration process: Effects of operating conditions on membrane fouling. Sep Purif Technol 76(3):292-302. https://doi.org/10.1016/j. seppur.2010.10.018

15. Wu Y, Zhang Z, He P, Ren H, Wei N, Zhang F, Cheng H, Wang Q (2019) Membrane fouling in a hybrid process of enhanced coagulation at high coagulant dosage and cross-flow ultrafiltration for deinking wastewater tertiary treatment. J Clean Prod 230:1027-1035 https://doi.org/10.1016/j.jclepro.2019.05.139

16. Zorpas A, Coumi C, Drtil M, Voukalli I (2011) Municipal sewage sludge characteristics and waste water treatment plant effectiveness under warm climate conditions. Desalin Water Treat. 36: 319-333. https://doi.org/10.5004/dwt.2011.2773, 1-3

17. Meiramkulova K, Zorpas AA, Orynbekov D, Zhumagulov M, Saspugayeva G, Kydyrbekova A, Mkilima T, Inglezakis VJ (2020) The effect of scale on the performance of an integrated poultry slaughterhouse wastewater treatment process. Sustainability 12(11):4679 https://doi.org/10.3390/su12114679

18. Simstich B, Beimfohr C, Horn H (2012) Lab scale experiments using a submerged MBR under thermophilic aerobic conditions for the treatment of paper mill deinking wastewater. Bioresour Technol 122:11-16 https://doi.org/10.1016/j. biortech.2012.04.029

19. Ho YC, Chua SC, Chong FK (2020) Coagulation-flocculation technology in water and wastewater treatment. In: Affam AC, Ezechi EH (eds) Handbook of Research on Resource Management for Pollution and Waste Treatment. IGI Global, Hershey. https://doi.org/10.4018/978-1-7998-0369-0.ch018

20. Teh CY, Budiman PM, Shak KP, Wu TY (2016) Recent advancement of coagulation-flocculation and its application in wastewater treatment. Ind Eng Chem Res 55(16):4363-4389. https://doi.org/10.1021/acs.iecr.5b04703

21. Jeldres RI, Fawell PD, Florio BJ (2018) Population balance modelling to describe the particle aggregation process: a review. Powder Technol 326:190-207. https://doi.org/10.1016/j.powtec.2017.12.033

22. Thill A, Moustier S, Aziz J, Wiesner MR, Bottero JY (2001) Flocs restructuring during aggregation: experimental evidence and numerical simulation. J Colloid Interface Sci 243(1):171-182. https://doi.org/10.1006/jcis.2001.7801

23. Yu WZ, Gregory J, Campos L, Li G (2011) The role of mixing conditions on floc growth, breakage and re-growth. Chem Eng 171(2):425-430. https://doi.org/10.1016/j.cej.2011.03.098

24. Kan C, Huang C, Pan JR (2002) Time requirement for rapid-mixing in coagulation. Colloids Surf A Physicochem Eng Asp 203(1-3):1-9. https://doi.org/10.1016/50927-7757(01)01095-0

25. Zhao L, Dai T, Qiao Z, Sun P, Hao J, Yang Y (2020) Application of artificial intelligence to wastewater treatment: a bibliometric analysis and systematic review of technology, economy, management, and wastewater reuse. Process Saf Environ Prot 133:169-182 https://doi.org/10.1016/.jpsep.2019.11.014

26. Wang D, Thunéll S, Lindberg U, Jiang L, Trygg J, Tysklind M, Souihi N (2021) A machine learning framework to improve effluent quality control in wastewater treatment plants. Sci Total Environ 784:147138 https:/doi.org/10.1016/j.scitotenv.2021.147138

27. Niu G, Yi X, Chen C, Li X, Han D, Yan B, Huang M, Ying G (2020) A novel effluent quality predicting model based on genetic-deep belief network algorithm for cleaner production in a full-scale paper-making wastewater treatment. J Clean Prod 265:121787 https://doi.org/10.1016/j.jclepro.2020.121787

28. Tao P, Sun Z, Sun Z (2018) An improved intrusion detection algorithm based on GA and SVM. IEEE Access 6:1362413631. https://doi.org/10.1109/ACCESS.2018.2810198

29. Srinivasan V, Ramalingam V, Sellam V (2012) Classification of Normal and Pathological Voice using GA and SVM. Int J Comput Appl 60(3):34-39. https://doi.org/10.5120/9675-4102

30. Luo Z, Hasanipanah M, Bakhshandeh Amnieh H, Brindhadevi K, Tahir MM (2021) GA-SVR: a novel hybrid data-driven model to simulate vertical load capacity of driven piles. Eng Comput 37(2):823-831 https:/doi.org/10.1007/s00366-019-00858-2

31. Chauhan VK, Dahiya K, Sharma A (2019) Problem formulations and solvers in linear SVM: a review. Artif Intell Rev 52(2): 803-855 https://doi.org/10.1007/s10462-018-9614-6

32. Kouziokas GN (2020) SVM kernel based on particle swarm optimized vector and Bayesian optimized SVM in atmospheric particulate matter forecasting. Appl Soft Comput 93:106410 https://doi.org/10.1016/j.asoc.2020.106410

33. Castro-Neto M, Jeong YS, Jeong MK, Han LD (2009) Online-SVR for short-term traffic flow prediction under typical and atypical traffic conditions. Expert Syst Appl 36(3):6164-6173 https://doi.org/10.1016/j.eswa.2008.07.069

34. Granata F, Papirio S, Esposito G, Gargano R, De Marinis G (2017) Machine learning algorithms for the forecasting of wastewater quality indicators. Water 9(2):105 https://doi.org/10.3390/w9020105

35. Rasmussen CE (2004) Gaussian processes in machine learning. In: Bousquet O, von Luxburg U, Rätsch G (ed) Advanced Lectures on Machine Learning. ML 2003. Lecture Notes in Computer Science, vol 3176. Springer, Heidelberg. https://doi. org /10.1007/978-3-540-28650-9-4.

36. Zhang N, Xiong J, Zhong J, Leatham K (2018) Gaussian process regression method for classification for highdimensional data with limited samples. In: Eighth International Conference on Information Science and Technology (ICIST), Andalusia, Spain, June 30-July 6 2018. doi: https://doi.org/10.1109/ICIST.2018.8426077

37. Liu H, Yang C, Huang M, Wang D, Yoo C (2018) Modeling of subway indoor air quality using Gaussian process regression. J Hazard Mater 359: 266-273. https://doi.org/10.1016/ j.jhazmat.2018.07.034, DOl: https://doi.org/10.1016/j.jha zmat.2018.07.034

38. Cho JH, Sung KS, Ha SR (2004) A river water quality management model for optimizing regional wastewater treatment using a genetic algorithm. J Environ Manag 73(3):229-242 https://doi.org/10.1016/j.jenvman.2004.07.004

39. Haldurai L, Madhubala T, Rajalakshmi R (2016) A study on genetic algorithm and its applications. Int J Comput Sci Eng 4(10):139-143

40. Gao BY, Yue QY, Wang BJ, Chu YB (2003) Poly-aluminum-silicate-chloride (PASiC) - a new type of composite inorganic polymer coagulant. Colloids Surf. A: Physicochem Eng Asp 229(1-3):121-127. https://doi.org/10.1016/j.colsurfa.2003.07.005

41. Zouboulis Al, Tzoupanos ND (2009) Polyaluminium silicate chloride-a systematic study for the preparation and application of an efficient coagulant for water or wastewater treatment. J Hazard Mater 162(2-3):1379-1389. https://doi. org/10.1016/j.jhazmat.2008.06.019

42. Zhang Q, Deng D, Dai W, Li J, Jin X (2020) Optimization of culture conditions for differentiation of melon based on artificial neural network and genetic algorithm. Sci Rep 10(1):1-8 https://doi.org/10.1038/541598-020-60278-x 
43. Zhang $Y, X U X$ (2020) Relative cooling power modeling of lanthanum manganites using Gaussian process regression. RSC Adv 10(35):20646-20653. https://doi.org/10.1039/DORA03031G

44. Li X, Lim BS, Zhou JH, Huang S, Phua SJ, Shaw KC, Er MJ (2009) Fuzzy neural network modelling for tool wear estimation in dry milling operation. In: Annual Conference of the PHM Society, San Diego, USA, September 27 - October 12009

45. Katoch S, Chauhan SS, Kumar V (2021) A review on genetic algorithm: past, present, and future. Multimed Tools Appl 80(5):8091-8126. https://doi.org/10.1007/s11042-020-10139-6

46. Duan J, Gregory J (2003) Coagulation by hydrolysing metal salts. Adv Colloid Interf Sci 100:475-502. https://doi.org/10.1 016/S0001-8686(02)00067-2

47. Lin JL, Pan JR, Huang C (2013) Enhanced particle destabilization and aggregation by flash-mixing coagulation for drinking water treatment. Sep. Purif. Technol. 115:145-51. https://doi.org/10.1016/j.seppur.2013.05.013

\section{Publisher's Note}

Springer Nature remains neutral with regard to jurisdictional claims in published maps and institutional affiliations.

Submit your manuscript to a SpringerOpen ${ }^{\circ}$ journal and benefit from:

- Convenient online submission

- Rigorous peer review

- Open access: articles freely available online

- High visibility within the field

- Retaining the copyright to your article

Submit your next manuscript at $\boldsymbol{\nabla}$ springeropen.com 